\title{
MATERNAL FACTORS AFFECTING LOW BIRTH WEIGHT IN URBAN AREA OF BANGLADESH
}

\author{
AZIMUL SK ${ }^{1}$, MATIN A ${ }^{2}$, SHABNAM JH ${ }^{3}$, SHAMIANAZ $\mathrm{S}^{4}$, BANEERJE $\mathrm{M}^{5}$
}

\begin{abstract}
:
Objectives: In Bangladesh low birth weight $(L B W)$ rate is quite high even in urban area. The present study was conducted to determine the maternal factors (e.g. socioeconomic, nutritional and pregnancy related) affecting $L B W$ in urban community of Bangladesh. Methods: This case control study was done at Shaheed Shohrawardy Medical College Hospital, Dhaka. Normally delivered singleton live births babies from January 2003 to January 2005 in obstetrics wards were selected purposively and after enrollment all newborn's birth weight was measured. Then from the total $(N=583)$ study populations child-mother pairs formed and were divided in $L B W$ group ( $n=135)$ and normal birth weight (NBW) group ( $n=448)$. Maternal socioeconomic, nutritional and pregnancy regarding data (e.g. parity, inter pregnancy interval, number of antenatal visits) were collected and then variables were analyzed to find out maternal factors affecting $L B W$.
\end{abstract}

Results: The LBW incidence was found $23.2 \%$ and mean birth weight was found $2762 \mathrm{gm}$. More proportion of $L B W$ babies came from the mother of $<20 y e a r$ of age group. Significant relationship was found between early maternal age, education, socioeconomic status, anaemia, iron \& vitamin supplementation during pregnancy, maternal weight, body mass index (BMI) with LBW. Parity, inter pregnancy interval and number of antenatal visit were also found significant risk factors for $L B W$. No relationship was found between tobacco use and maternal height with $L B W$.

Conclusion: Among the various epidemiological factors the maternal factors like antenatal care, parity, inter pregnancy interval, iron \& vitamin supplementation during pregnancy are found to influence birth weight. Hence, it is the need of the hour to strengthen the existing maternal services at the community level to reduce LBW in Bangladesh.

Key words: LBW (Low Birth Weight), NBW (Normal Birth Weight).

J Dhaka Med Coll. 2009; 18(1) : 64-69

\section{Introduction:}

Birth weight is the first weight of the foetus or newborn obtained after birth preferably measured within the first hour of life before significant postnatal weight loss has occurred. Low birth weight (LBW) is defined as that less than 2,500 gm. More than twenty million LBW babies were born every year throughout the world and about $15.5 \%$ of all births are born with LBW $^{1}$. Ninety percent $(90 \%)$ of these LBW babies' are born in developing countries. In spite of consistent efforts to improve the quality of maternal and child health LBW rate is quite high in Bangladesh. According to national low birth weight survey of Bangladesh (2003-2004) LBW rate is $36 \%$. Half of all perinatal deaths are directly or indirectly related to $\mathrm{LBW}^{2}$. Infants are born with low weight either because they are premature $(<37$ weeks gestation at birth) and/or because they suffered intrauterine growth retardation. The majority of LBW infants in developing countries are intra uterine growth retardation (IUGR) ${ }^{3}$. The shorter the gestation and the smaller the baby, higher the risk of morbidity and mortality. Low birth weight due to restricted fetal growth (IUGR) has a poor prognosis compared to that due to preterm birth.

It is generally acknowledged that the etiology of LBW is multifactorial ${ }^{4,5}$. During the fetal phase, growth depends on the nutritional condition of the mother, indicating that

1. Assistant Professor, Department of Paediatrics, Dhaka Medical College, Dhaka.

2. Assistant Professor, Department of Paediatric Hematology \& Oncology, Dhaka Medical College, Dhaka.

3. Registrar, Department of Cardiology, BIRDEM Hospital, Dhaka.

4. Lecturer, FWVTC, Azimpur, Dhaka.

5. Assistant Professor, Department of Neonatology, Dhaka Medical College, Dhaka.

Correspondence: Dr. Sk. Azimul Hoque 
pregnant women should not only increase their weight but also consume essential nutrients. For many women in the developing world however, economic, social and cultural factors make it difficult for them to obtain the necessary food and health care, which are closely interrelated 6-8. The biological processes that affect the foetus in utero are related to the mother's nutrition, exercise, infections and consumption of tobacco by chewing or smoking, alcohol and other drugs. Low birth weight is strongly associated with undernutrition in mothers and about half of all IUGR in developing countries is attributable to low maternal weight, low weight gain during pregnancy and iron deficiency anaemia 9-13. Multiple gestations are high risk pregnancies, which may be complicated by pre-maturity, low birth weight infants, preeclampsia, anemia, postpartum hemorrhage, intrauterine growth restriction, neonatal morbidity and high perinatal, neonatal and infant mortality. The rate of multiple gestation pregnancies has grown exponentially over the last few decades and is responsible for the steady increase in the rate of low birth weight infants. As a group, infants of multiple gestation pregnancies have higher mortality and morbidity than singleton pregnancies, 11 . Mothers who are $<20$ years or $>35$ years old are more likely to give birth to LBW infants ${ }^{4,5,14}$. Neonatal survival depends on both gestational maturity and birth weight $^{2,14,15}$. The beneficial effects of good antenatal care on pregnancy outcome have been described in many observational studies over several decades ${ }^{5,13,16}$. LBW survivors demonstrate significant growth retardation, as reflected by lower body weights, heights and head circumferences, in comparison to normal weight peers ${ }^{16-18}$. Although there is some tendency for catch up growth, the deficits persist even up till 14 years of age ${ }^{19-21}$. The catch up is more for the preterm births in contrast to the growth retarded subjects. There is evidence of delayed skeletal growth and maturation in children aged between 6 to 10 years ${ }^{22}$. While delayed puberty has been reported in LBW children ${ }^{23,24}$. Earlier onset of menarche was documented in a longitudinal follow up study ${ }^{19}$. These growth retarded adult women (stunted and underweight) are likely to give birth to LBW babies thereby perpetuating a vicious cycle through generations. The socio-economic factors are income, education, occupation affect birth weight. Other important factors are parity; inter pregnancy interval, quality and number of antenatal care along with nutrition education affect birth weight ${ }^{6,8,25-29}$. The individual effect and magnitude of each of the factors for LBW is still debatable. On the basis of available evidence this study will highlight selected independent factors (e.g. socioeconomic, nutritional and pregnancy related) affecting LBW in urban area and that would have contributed in reducing the incidence of low birth weight in Bangladesh.

\section{Methodology:}

This study was a case control study and was done at Shaheed Shohrawardy Medical College Hospital, Dhaka, Bangladesh from January 2003 to January 2005. All babies with birth weight less than 2,500 gm were labeled as low birth weight (LBW) group and were compared with Normal birth weight (NBW) babies weight $2,500 \mathrm{gm}$ or more as control group. From the department of Gynae \& Obstetrics samples were selected purposively following the inclusion criteria: alive baby born by normal delivery. Exclusion criteria were as follows: still born babies, baby born by caesarian section, babies with congenital anomalies, baby born by multiple pregnancies, baby with maternal history of complications (e.g eclampsia and preeclampsia, diabetes mellitus, heart disease, jaundice, chronic lung disease etc.) After enrollment in this study weight of all newborns were measured. NNC weighing scale was used to measure birth weight of the babies just after the delivery. Then the total $(\mathrm{N}=583)$ study populations were divided in two groups. All babies with birth weight less than 2,500 gm at birth were labeled as low birth weight (LBW) group $(n=135)$ and birth weight 2,500 gm or more at birth were labeled as Normal birth weight (NBW) group(n=448).

Informations were collected from the mothers through face to face interview by structured interview form. Questionnaire was completed 
within 24 hours of birth. Data were collected for age, socioeconomic status, educational status, anaemia, intake of iron and vitamins. Socioeconomic status was classified according to income as below average group $<1500$ taka /person/month, and above average group $>1500$ taka/person/month. Data regarding parity, inter pregnancy interval and number of antenatal visit, history of tobacco intake were also collected. Height, weight were measured of all mothers and Body mass index (BMI) was calculated as weight in $\mathrm{kg}$ divided by height in square meter $\left(\mathrm{Kg} / \mathrm{M}^{2}\right)$. Data were analyzed by standard statistical formula using statistical package for social science program (SPSS 11.0 version). Chi square $\left(\mathrm{c}^{2}\right)$ test was used for comparative analysis between two groups of study population. At 95\% confidence limit $\mathrm{p}$ value $<0.05$ was labeled as significant. Informed consent was taken from mothers before enrolment in this study.

\section{Results:}

After fulfilling inclusion and exclusion criteria total 583 babies were included in this study. Out of 583 babies 135 babies were found LBW and 448 babies were found NBW. The LBW prevalence was $23.2 \%$ and mean birth weight was $2762 \mathrm{gm}$ in this study. Among total 583 babies 296(50.1\%) were female and 287(49.9\%) were male. In LBW group 69 were female and 66 were male besides 227 were female and 221 were male in NBW group. No relation was found between birth weight and sex of the baby. Majority of the LBW 69/135(51.1\%) came from the mother of $<20 y e a r$ of age group and most of the NBW $327 / 448(73 \%)$ came from the mother of 20-30years age group showing association between LBW and early maternal age. Most of the LBW $67 / 135(50 \%)$ came from the mother without education but in NBW group 165/ $448(37 \%)$ came from the mother completed primary education and $238 / 448(53 \%)$ from mother who completed secondary level or above. These data showed significant relationship between LBW and poor educational status. Majority of the mother came from below average socioeconomic status but it was more in LBW $107 / 135(79.2 \%)$ in comparison to mother of NBW 302/448(67.4\%) showing association between LBW and poor socioeconomic status.

Table-I

Shows maternal socio-economic factors affecting birthweight

\begin{tabular}{lccc}
\hline Risk factors & $\begin{array}{c}\text { LBW babies } \\
(\mathrm{n}=135)\end{array}$ & $\begin{array}{c}\text { NBW babies } \\
(\mathrm{n}=448)\end{array}$ & $\mathrm{p}$ value \\
\hline Age & 69 & 79 & $\mathrm{p}<0.001^{*}$ \\
$\quad<20$ years & 36 & 327 & \\
20-30 years & 30 & 42 & \\
$\quad>30$ years & 108 & 356 & $\mathrm{p}>0.05$ \\
Resident area & 27 & 92 & \\
$\quad$ Urban & & & $\mathrm{p}<0.01^{*}$ \\
$\quad$ Rural & 102 & 334 & \\
Occupation & 33 & 114 & $\mathrm{p}<0.001^{*}$ \\
$\quad$ Housewife & & & \\
$\quad$ working & 67 & 45 & \\
Educational status & 41 & 165 & $\mathrm{p}<0.01^{*}$ \\
$\quad$ Illiterate & 27 & 238 & \\
$\quad$ upto primary & & & \\
$\quad$ Secondary \& above & 107 & 302 & \\
Socioeconomic status & 28 & 146 & \\
$\quad$ Below average & & & \\
$\quad$ Above average & & &
\end{tabular}


Most of the mothers (52.6\%) were found anemic who gave birth LBW and anaemia was absent among majority (67.9\%) of the mothers of NBW showing association between LBW and maternal anaenia during pregnancy. Iron \& vitamin supplementation during pregnancy were found significantly less among the mothers of LBW babies $69.6 \%(94 / 135)$ and it was more in mothers of NBW babies $82.4 \%$ (369/448). Those data showing significant positive effect of iron \& vitamin supplementation during pregnancy and negative effect of maternal anaemia on birth weight. No differences were found considering maternal height between two groups but significant relationship was found between maternal weight and birth weight. Maternal BMI was found significantly low among LBW group showed positive impact of maternal BMI on birth weight. Maternal anxiety or depression was found more commonly among the mothers of LBW babies $60 \%(81 / 135)$ whereas it was only $27.7 \%$ (124/448) among the mothers of NBW babies reflecting significant negative effect of maternal anxiety or depression on birth weight.

Table II also shows amongst the mothers of LBW there were a significantly greater proportion of primiparas $45.9 \%(62 / 135)$ in comparison to NBW $37.7 \%$ (169/448). Last pregnancy interval

Table-II

Shows maternal factors affecting birthweight

\begin{tabular}{|c|c|c|c|}
\hline Risk factors & $\begin{array}{c}\text { LBW babies } \\
(\mathrm{n}=135)\end{array}$ & $\begin{array}{c}\text { NBW babies } \\
(n=448)\end{array}$ & $\mathrm{p}$ value \\
\hline \multicolumn{4}{|l|}{$\overline{\text { Age }}$} \\
\hline$<20$ years & 69 & 79 & $\mathrm{p}<0.001^{*}$ \\
\hline 20-30 years & 36 & 327 & \\
\hline >30 years & 30 & 42 & \\
\hline \multicolumn{4}{|l|}{ Parity } \\
\hline Primi & 62 & 169 & $\mathrm{p}<0.01^{*}$ \\
\hline Multiparous & 73 & 279 & \\
\hline \multicolumn{4}{|c|}{ Inter pregnancy interval } \\
\hline$<2$ years & 72 & 201 & $\mathrm{p}<0.01^{*}$ \\
\hline 2years or more & 63 & 247 & \\
\hline \multicolumn{4}{|l|}{ No. of antenatal visit } \\
\hline$<2$ & 70 & 30 & $\mathrm{p}<0.001^{*}$ \\
\hline$>2$ to 4 & 46 & 121 & \\
\hline$>4$ & 19 & 297 & \\
\hline \multicolumn{4}{|c|}{ Iron $\&$ vitamin supplementation } \\
\hline Yes & 94 & 369 & $\mathrm{p}<0.01^{*}$ \\
\hline No & 41 & 79 & \\
\hline \multicolumn{4}{|c|}{ Tobacco smoking or chewing } \\
\hline Yes & 19 & 51 & $\mathrm{p}>0.05$ \\
\hline No & 116 & 397 & \\
\hline \multicolumn{4}{|l|}{ Maternal anaemia } \\
\hline Yes & 71 & 144 & $\mathrm{p}<0.001^{*}$ \\
\hline No & 64 & 304 & \\
\hline \multicolumn{4}{|l|}{ Maternal Height } \\
\hline$<1.55$ meter & 41 & 152 & $\mathrm{p}>0.05$ \\
\hline$>1.55$ meter & 84 & 296 & \\
\hline \multicolumn{4}{|l|}{ Maternal Weight } \\
\hline$<55 \mathrm{Kg}$ & 53 & 133 & $\mathrm{p}<0.001^{*}$ \\
\hline$>55 \mathrm{Kg}$ & 82 & 315 & \\
\hline \multicolumn{4}{|c|}{ Maternal BMI in $\mathrm{Kg} / \mathrm{M}^{2}$} \\
\hline$<19$ & 41 & 59 & $\mathrm{p}<0.01^{*}$ \\
\hline$>19$ & 84 & 389 & \\
\hline
\end{tabular}


was found short (<2 years) among 53.3\% (72/ $135)$ in LBW group and $44.9 \%(201 / 448)$ in NBW group, showing statistically significant association between short last pregnancy interval $(<2$ years) and LBW. Number of antenatal visits were found $(<2)$ in $51.9 \%$ (70/ 135 ) cases of LBW group in comparison to only $6.7 \%(30 / 448)$ in NBW group. Number of antenatal visits were found (>4) only in $14 \%$ (19/135) cases of LBW group and 66.3\% (297/ 448) in NBW group showing highly significant relationship between less number of antenatal visits and LBW. Significant effect of maternal tobacco smoking or chewing on birth weight was not found in this study.

\section{Discussion:}

Mean birth weight was found 2762 gm in this study and that was 2961 gm by Hosain G. et al 28 and 2669 gm by Deshmukh J. et al ${ }^{4}$. The LBW incidence in this study showed $23.2 \%$ which was similar to Hosain G. et al ${ }^{28}$ where they found $24 \%$ in their study. But national low birth weight survey of Bangladesh (2003-2004) showed $36 \%$ and that difference may be explained as our study was done in an urban area which does not reflect the true scenario of Bangladesh. Significant association was found in our study between LBW and early maternal age $(<20$ year) which is also seen by other study 5,6,28. Finding of statistically significant relation of LBW with maternal socioeconomical status and educational level are consistent with the study of Nair NS.et $\mathrm{al}^{14}$ - Maternal anaemia was found significantly more common in LBW and iron \& vitamin supplementation during pregnancy were found significantly less among the mothers of LBW babies in comparison to NBW Those data showed significant positive effect of iron \& vitamin supplementation during pregnancy and negative effect of maternal anaemia on birthweight, which is similar to other study $6,9,29$ and differ from study of Khatun S, Rahman $M^{8}$. No relationship was found between LBW and maternal height which observation was same by Hosain G. et al ${ }^{28}$. Maternal weight and BMI were found as significant risk factors for LBW that was also found by Borja JB et $\mathrm{al}^{9}$ and Mavalankar DV et al ${ }^{12}$. Among the LBW there were a significantly greater proportion of primiparas in comparison to NBW, significant association between short last pregnancy interval $(<2$ years) and LBW alongside highly significant relationship between less number of antenatal visits and LBW. These observations were also found in other studies ${ }^{5,11,13}$. Significant effect of tobacco smoking on LBW was not found in this study like Nair NS.et $\mathrm{al}^{14}$. There were limitation in this study as it was done in an urban area thus it can not be the true representative of the country scenario. As there are several factors interacting in this phenomenon so it was not feasible to single out any particular factor affecting low birth weight. Among the various epidemiological factors the maternal factors like age of pregnancy, antenatal care, parity and iron $\&$ vitamin supplementation during pregnancy are found to influence birth weight. To reduce LBW in Bangladesh strategically we have to focus more to expand \& strengthen the existing maternal services at the community level, which will improve antenatal health care and thereby reduce LBW in our country.

\section{Conclusion:}

In this study significant relationship was found between early maternal age, education, socioeconomic status, anaemia, iron $\&$ vitamin supplementation during pregnancy, weight, BMI, parity; inter pregnancy interval and number of antenatal visit with LBW. To prevent and reduce LBW prevelance in urban bangladesh along with rural area we have to fix strategy, have to give more attention towards awareness building to increase inter pregnancy interval and number of antenatal visit along with iron \& vitamin supplementation during pregnancy and discouraging teenage pregnancy.

\section{References:}

1. State of world children, UNICEF-2004, available athttp://www.unicef.org/publications / index.html

2. Gazi R, Karim F, Ali A. Low birth weight was the major predictor of infant deaths: Evidence from aprospective study in rural Bangladesh. Brac Research Annual report, 2001 
3. Fikree FF, Berendes HW. Risk factors for term intrauterine growth retardation: a communitybased study in Karachi. Bull World Health Org, 1994; 72:581-587.

4. Deshmukh J, Motghare DD, Zodpey SP, Wadhva SK. low birth weight and associated maternal factors in urban area. Indian Pediatr 1998; 35:3336

5. Aurora S, Vishnu B. Habibullah S, Srinivasan S, Puri RK, Rajaram P. Maternal nutrition and birth weight. Indian J Mat Child Hlth 1994; 5: 73-75.

6. Valero DE, Bernabé J, Soriano T, Albaladejo R, Juarranz M, Calle ME, Martínez D, DomínguezRojas V. Risk factors for low birth weight: a review. Eur J Obstet Gynecol Reprod Biol 2004; 116:315 .

7. Kramer MS. Determinants of low birth weight. Bull World Health Org 1987; 65:663-737.

8. Khatun S, Rahman M. Socio-economic determinants of low birth weight in Bangladesh: A multivariate approach BMRC Bull 2008; 34: 8186

9. Borja JB, Adair LS. Assessing the net effect of young maternal age on birthweight. Am J Hum Biol 2003; 15:733-40.

10. Khan MM. Effect of maternal anaemia on fetal parameters. J Ayub Med Coll Abbottabad 2001; $13: 38-41$

11. Kilsztajn S, Rossbach A, Carmo MS, Sugahara GT. Prenatal care, low birth weight and prematurity Rev Saude Publica. 2003; 37: 303-10.

12. Mavalankar DV, Gray RH, Trivedi CR. Risk factors for preterm and term low birthweight in Ahmedabad, India. Int J Epidemiol 1992; 21:26372 .

13. Munjanja SP, Lindmark G, Nystrom L. Randomized controlled trial of a reduced-visits program of antenatal care in Harare, Zimbabwe. Lancet 1996; 348:364-69.

14. Nair N, Rao RS, Chandrashekar S, Acharya D, Bhat HB. Socio-demographic and maternal determinants of low birth weight: A multivariate approach. Indian J Pediatr. 2000; 67: 9-14.

15. Naher N, Afroza S, Hossain M. Incidence of LBW in three selected communities of Bangladesh. BMRC Bull. 1998; 24: 49-54.

16. Begum R, Barua S. Birth weight in relation to other anthropometric indices and some biological and socioeconomic factors: A study in a city hospital. Bangladesh J Nutr. 1996; 9: 15-18.
17. Watanabe $\mathrm{H}$, Inoue $\mathrm{K}$, Doi $\mathrm{M}$, Matsumoto $\mathrm{M}$, Ogasawara K, Fukuoka H, Nagai Y. Risk factors for term small for gestational age infants in women with low prepregnancy body mass index. J Obstet Gynaecol Res. 2010 ;36:506-12.

18. Bhargava SK, Kumari S, Choudhury P, Ghosh S, Butani R. A longitudinal study of linear physical growth of infants with birth weight of $1500 \mathrm{~g}$ or less from birth to 6 years. Indian J Med Res 1983; 71: 78-82.

19. Bhargava SK, Ramji S, Srivastava U, Sachdev HP, Kapani V, Datta V, Satyanarayana L. Growth and sexual maturation of low birth weight children: A 14 year follow up. Indian Pediatr 1995; 32: 963-70.

20. Bavedekar AR, Vaidya UV, Bhave SA, Pandit AN. Catch up growth and its determinants in low birth weightbabies: A study using $Z$ scores. Indian Pediatr 1994; 31:1483-90.

21. Kalra SK, Sarkar P, Vatwani D, Dey NS. A longitudinal study of low birth weight babies. India J Pediatr' 1983; 50; 279-83.

22. Bhargava SK, Kumari S, Baijal VN, Bhan MK, Taneja S, Choudhury P. Skeletal maturation in children with birth weight of 2000 g or less. Indian J Med Res 1980; 71: 268-72.

23. Bhargava SK, Kumari S, Baijal VN, Bhan MK, Tanejas, Choudhury P. Patterns of pubertal changes and their interrelationships in girls. Indian Pediatr 1980; 17: 657-65.

24. Choudhari S, Kulkarni S, Pajnigar F, Pandit AN, Deshmukh S. A longitudinal follow-up of development of preterm infants. Indian Pediatr 1991; 28: 873-80.

25. Eriksson JG, Forsen T, Tuomilehto J, Winter PD, Osmond C, Barker DJ. Catch up growth in childhood and death from coronary heart disease: Longitudinal study. BMJ. 1999; 318: 427-431.

26. Badshah S, Mason L, McKelvie K, Roger P, Paulo L. Risk factors for low birthweight in the publichospitals at Peshawar. BMC Public Health. 2008; 8: 197-199.

27. Dhar B, Mowlah G, Kabir DM. Newborn anthropometry and its relationship with maternal factors. BMRC Bull. 2003; 29: 45-58.

28. Hosain G, Chatterjee N, Afroza B, Chandra S. Factors associated with low birthweight in rural Bangladesh. J Tropic. Pediatr. 2006; 52:87-91.

29. Negi KS, Kandpal SD, Kukreti M. Epidemiological Factors Affecting Low Birth Weight. Indian J Pediatr. 2006;8:31-34 